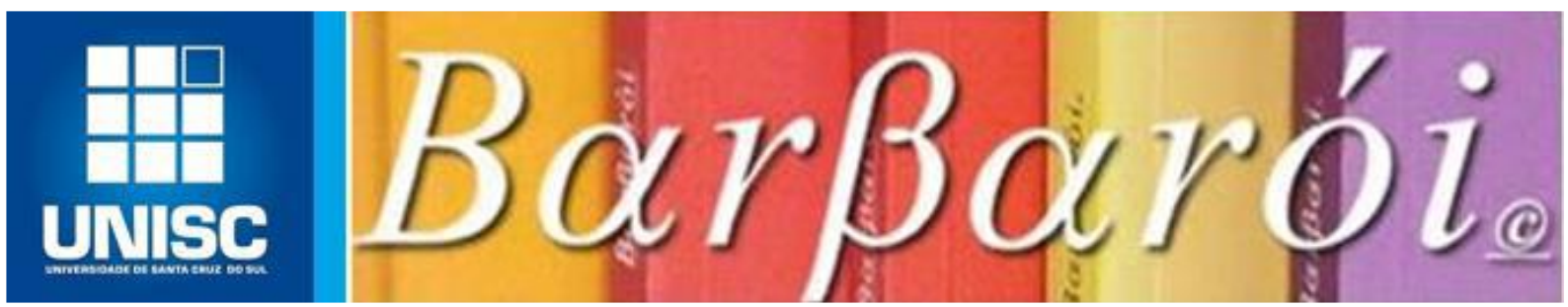

\title{
A PÓS-GRADUAÇÃO COMO LÓCUS DE FORMAÇÃO PARA A DOCÊNCIA: UMA EXPERIÊNCIA COM METODOLOGIAS ATIVAS DE ENSINO-APRENDIZAGEM NA ÁREA DA SAÚDE
}

\section{DOI: http://dx.doi.org/10.17058/barbaroi.v0i0.14825}

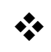 \\ Maria Eduarda de Carli Rodrigues \\ Universidade Federal de Santa Catarina - UFSC - Brasil \\ Raquel Antunes de Mello \\ Serviço Nacional de Aprendizagem Comercial - SENAC - Brasil \\ Carla Rosane Paz Arruda Teo \\ Universidade Comunitária da Região de Chapecó - Unochapecó - Brasil \\ Maria Elisabeth Kleba \\ Consultora e educadora autônoma - Brasil \\ Fátima Ferretti \\ Universidade Comunitária da Região de Chapecó - Unochapecó - Brasil

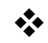

\section{Resumo}

O perfil profissional almejado pelo Sistema Único de Saúde requer uma formação baseada na problematização e que reconheça o estudante como corresponsável pela construção do conhecimento, promovendo seu desenvolvimento para além das dimensões técnico-científica e procedimental. Este texto problematiza uma prática de ensino realizada na educação superior, a partir de um programa de pós-graduação da área da saúde, fundamentada em metodologias ativas de ensino-aprendizagem. O objetivo deste trabalho foi problematizar as possibilidades de a pós-graduação assumir um papel protagonista na formação para a docência na área da saúde. $\mathrm{O}$ texto apresenta os pressupostos das metodologias ativas de ensino-aprendizagem que fundamentam a prática docente e, ao relatar a experiência realizada junto a um curso de graduação, a problematiza. A reflexão desenvolvida evidencia a importância de que a pósgraduação assuma a condição de lócus privilegiado para a formação docente.

Palavras-chave: Prática docente; Educação superior; Modelos educacionais. 


\section{Introdução}

Os movimentos sociais das décadas de 1970 e 1980 no Brasil, em especial a Reforma Sanitária, tiveram na $8^{\text {a }}$ Conferência Nacional de Saúde, em 1986, um marco paradigmático que resultou na conquista da saúde como direito universal. Inscrito na Constituição Federal de 1988, esse direito passa a ser garantido a partir da Lei $n^{\circ} 8.080$, que regulamenta o Sistema Único de Saúde (SUS) do país (BRASIL, 1988; BRASIL, 1990a; FURTADO; CARVALHO, 2015).

A partir de sua implementação, o SUS passa a assumir a prerrogativa de ordenador da formação dos profissionais de saúde no Brasil, a qual mantém ainda hoje forte influência do Relatório Flexner, considerado o grande responsável pela mais importante reforma das escolas médicas nos Estados Unidos (PAGLIOSA; DA ROS, 2008; HORA et al., 2013). Essa reforma exerceu profundas implicações para a formação profissional em saúde em âmbito internacional, inclusive no Brasil, caracterizada pela fragmentação de conteúdos e práticas, com reflexos na concepção de ser humano, com foco na especialização, na abordagem curativa e no profissional médico como responsável pela condução de todo o processo terapêutico (PAGLIOSA; DA ROS, 2008; HORA et al., 2013). Esse modelo biomédico de formação tem sido amplamente criticado, à medida que não corresponde aos referenciais de saúde e doença ou de ser humano que fundamentam os princípios e diretrizes do SUS (GENTIL; ABILIO; CORDEIRO, 2015).

Nessa perspectiva, destaca-se a necessidade de mudança nos modelos pedagógicos com vistas a desenvolver habilidades para uma atuação coerente com as necessidades do SUS (FREITAS et al., 2013; LEAL et al., 2015), que problematize e integre saberes e práticas profissionais (ABRAHÃO; MERHY, 2014).

A incongruência entre modelo de formação e modelo de atenção preconizado pelo SUS exigiu iniciativas dos Ministérios da Saúde e da Educação, no sentido de promover as mudanças necessárias no âmbito do ensino superior, considerando a importância do papel dos profissionais da área para a viabilização e consolidação do sistema de saúde.

A Lei de Diretrizes e Bases da Educação Nacional (LDB) e as Diretrizes Curriculares Nacionais (DCN) vigentes para os cursos de graduação reforçam essa reformulação. De acordo com esses documentos, o estudante deve ser estimulado a conhecer os problemas concretos do mundo atual em sua complexidade, desenvolvendo senso crítico, competência reflexiva e capacidade de transformar a realidade (BRASIL, 1996; BRASIL, 2001).

Tais aspectos são coerentes com a educação problematizadora de Freire (2005), a qual propõe a reflexão dos homens sobre suas relações com o mundo de forma autêntica, articulada, crítica e capaz de transformá-lo, por se fundar no diálogo, na criatividade, na reflexão, na 
autonomia, no reconhecimento da historicidade do ser humano e na percepção de sua inconclusão, esteja ele no papel de educador ou de educando.

Além disso, outras articulações (Projetos IDA e UNI, Rede Unida, PROMED, VERSUS, Aprender-SUS, Ensina-SUS, Pró-Saúde, PET-Saúde) ${ }^{1}$ buscaram favorecer a reorientação da formação dos profissionais de saúde, tendo como estratégia central a integração entre instituições de ensino e serviços de saúde, com a valorização de todos os envolvidos, em um processo de construção coletiva (CECCIM; FEUERWERKER, 2004; DIAS; LIMA; TEIXEIRA, 2013).

Mesmo diante dos esforços empreendidos, o desafio de formar profissionais de saúde para o SUS permanece, certamente pela complexidade do processo de ensino-aprendizagem e do próprio trabalho em saúde. Entre os diversos aspectos implicados com o desafio de formar profissionais preparados para consolidar o SUS, destaca-se a necessidade de construir mecanismos e estratégias pedagógicas para superar o modelo tradicional e acrítico de ensino ainda tão presente na educação superior. Contudo, a atenção a novas concepções e formas de ensinar na saúde não deve estar restrita ao âmbito dos saberes e fazeres profissionais específicos desse campo. Ou seja, é fundamental que a formação de profissionais da saúde passe a assumir também, entre suas dimensões, a qualificação para a docência, como compromisso com a educação das futuras gerações de profissionais.

A esse respeito, a literatura tem apontado os profissionais de saúde como especialistas nesse campo, carecendo, no entanto, de formação para a docência (TREVISO; COSTA, 2017). Assim, o docente na área da saúde se torna educador mais por seu domínio de conhecimentos específicos relativos à sua área de atuação profissional do que propriamente por sua competência pedagógica. Dito de outra forma, os docentes na saúde tornam-se professores sem ter formação para tanto, cenário que vem se exacerbando pela significativa expansão do ensino superior nas últimas décadas (PAULINO et al., 2017).

É pertinente supor, diante dessas considerações, que o despreparo pedagógico dos profissionais de saúde que assumem atividades docentes na educação superior seja um dos fatores implicados com as dificuldades em produzir avanços mais expressivos em termos de

\footnotetext{
${ }^{1}$ Programa de Integração Docente Assistencial (IDA), criado no âmbito do Ministério da Educação; Projeto UNI - Uma Nova Iniciativa, financiado pela Fundação Kellogg, a fim de redimensionar questões relativas ao Programa IDA; Programa Nacional de Incentivo a Mudanças Curriculares nos Cursos de Medicina (PROMED); Projeto Vivências e Estágios na Realidade do Sistema Único de Saúde - VER-SUS; AprenderSUS teve papel relevante no debate em torno da integralidade da atenção à saúde como eixo de mudança da formação profissional; o projeto EnsinaSUS contemplou uma série de pesquisas e experiências inovadoras de mudanças na formação e educação permanente em saúde; Programa Nacional de Reorientação da Formação Profissional em Saúde - Pró-Saúde; Programa de Educação pelo Trabalho para a Saúde - PET-Saúde.
}

Barbarói, Santa Cruz do Sul, n. 56, p.<104-126>,jan./jun. 2020 
mudanças dos processos de formação no sentido de sua coerência com os princípios e diretrizes do SUS.

Reconhecendo a importância de formação específica para a docência na área da saúde, destaca-se que as oportunidades para isso, no geral, estão restritas à pós-graduação, principalmente no nível stricto sensu. Contudo, usualmente, a pós-graduação tem priorizado a formação para a pesquisa em detrimento da docência (BACKES et al., 2013; PAULINO et al., 2017; TREVISO; COSTA, 2017).

Argumenta-se, assim, que a pós-graduação deve assumir papel relevante quanto à formação docente de profissionais da saúde, promovendo o debate sobre o tema, valorizando a prática pedagógica e favorecendo o desenvolvimento de novas posturas docentes, assim como a adoção de metodologias de ensino-aprendizagem mais coerentes com o perfil profissional requerido pelo SUS (PAULINO et al., 2017). Essas proposições estão ancoradas na intencionalidade não só de instrumentalizar o (futuro) professor como também - e especialmente - de mobilizá-lo para a formação docente em uma perspectiva permanente (TREVISO; COSTA, 2017).

Frente à relevância das questões abordadas, este texto relata uma experiência pedagógica, relativa à prática de ensino na educação superior em saúde, fundamentada em metodologias ativas de ensino-aprendizagem. A experiência foi realizada no âmbito de uma disciplina voltada à docência, e seu relato é apresentado com vistas a problematizar as possibilidades de a pós-graduação stricto sensu assumir um papel protagonista na formação para a docência na área da saúde.

Esclarece-se que este texto está organizado em algumas sessões, além desta de caráter introdutório: a próxima apresenta pressupostos assumidos pelas autoras acerca das metodologias ativas de ensino-aprendizagem; a seguinte trata da experiência pedagógica realizada em um curso de graduação; a final expõe as principais ponderações das autoras, a partir das reflexões desenvolvidas no percurso da experiência relatada.

\section{Metodologias ativas de ensino-aprendizagem: pressupostos da experiência}

Questões como a indissociabilidade entre teoria e prática, o desenvolvimento de uma visão integral do ser humano e a ampliação da concepção de cuidado são especificidades da área da saúde que revelam a importância de que sejam promovidas transformações metodológicas nos processos de formação profissional (MITRE et al., 2008).

Parte-se do pressuposto de que a educação transmissiva tradicional não contribui para esses aspectos, mas, ao contrário, estimula a passividade e a atitude pouco crítica do estudante, 
induzindo hábitos de anotar e memorizar, sem questionamento sobre fontes, conteúdos ou aplicabilidade das informações. Essa perspectiva se caracteriza, ainda, por pouca aproximação do estudante com a prática, com preferência pela especulação teórica e tendência ao racionalismo radical, individualismo e competitividade (LIMA, 2017).

A concepção transmissiva é semelhante à bancária, em que o educador é o depositante e os estudantes, os depositários, aos quais cabe receber, guardar e arquivar. Há, nela, um narrador que, ao invés de comunicar-se, faz comunicados de forma estática, alheia à experiência existencial, de conteúdos fragmentados, alienados e alienantes. Quem acaba por tornar-se arquivado são os estudantes, "arquivados, porque, fora da busca, fora da práxis, os homens não podem ser [...] nesta distorcida visão da educação, não há criatividade, não há transformação, não há saber" (FREIRE, 2005, p. 66-67).

Nesse contexto, é premente que os esforços se voltem para uma formação docente que fomente a adoção de novas metodologias de ensino-aprendizagem, mais favoráveis ao desenvolvimento de habilidades para além das técnicas e procedimentais, como reflexão, crítica, humanização, ética e capacidade de intervir e transformar a realidade (FREIRE, 2011).

Referenciais pedagógicos pautados pelas metodologias ativas de ensino-aprendizagem podem ser coerentes com esses propósitos, visto que incentivam o estudante a assumir o protagonismo em seu processo de formação (MITRE et al., 2008). Ainda, potencializam a corresponsabilidade entre professor e estudante no processo de formação profissional, por meio do diálogo, das relações de vínculo, confiança e reciprocidade (COTTA; MENDONÇA; COSTA, 2011). Portanto, apresentam potencial indutivo de mudanças que contribuam para a formação de profissionais preparados para intervir na realidade de forma crítica, coletiva e integradora (GIGANTE; CAMPOS, 2016).

Essa concepção, por sua vez, problematizadora, já não pode ser um ato de depositar e dominar, ao contrário, ela serve à libertação por meio da dialogicidade entre educador e educando, de modo que o educador não é o que apenas educa, mas aquele que, enquanto educa, é educado, tornando-se ambos, assim, sujeitos de um processo em que crescem, educando-se em comunhão, mediatizados pelo mundo (FREIRE, 2005).

Nessa lógica, estratégias pedagógicas ativas surgem como uma alternativa que promove a dialogicidade, a horizontalidade das relações e a aprendizagem em contexto, valorizando a interação do estudante com o assunto estudado, de forma que ele pergunte, discuta e construa seu conhecimento, em um movimento de ação-reflexão-ação em que o professor é o mediador do processo de ensino-aprendizagem (BARBOSA; MOURA, 2013). A educação crítica 
mobiliza a criatividade, estimulando ação e reflexão verdadeiras sobre a realidade e impulsionando à transformação (FREIRE, 2011).

Por definição, metodologias ativas são aquelas que colocam estudantes e professores em movimento e interação, nos diferentes domínios da aprendizagem - cognitivo, motor, afetivo, relacional (VASCONCELLOS, 2006) -, gerando uma ambiência favorável que repercute como sentido de engajamento, pertencimento, responsabilização e comprometimento (BERBEL, 2011). Essas metodologias, embasadas em processos interativos, envolvem a construção do conhecimento a partir de análises, estudos, pesquisas e decisões individuais e coletivas, utilizando experiências reais ou simuladas, visando ao desenvolvimento de condições para solucionar, com sucesso, desafios advindos das atividades essenciais da prática social, em diferentes contextos (BERBEL, 2011).

A categoria de metodologias ativas inclui uma diversidade de possibilidades, algumas das quais já bem delineadas, como a Problem Based Learning (PBL) ou Aprendizagem Baseada em Problemas (ABP), a Metodologia da Problematização (com o Arco de Charles Maguerez), a Team Based Learning (TBL) ou Aprendizagem Baseada em Equipes (ABE), o Círculo de Cultura, entre outras (PAIVA et al., 2016).

No entanto, cabe esclarecer que uma variedade de outras estratégias pedagógicas pode ser empregada na perspectiva das metodologias ativas, como seminários, atividades em pequenos grupos, relatos de experiência, socialização e exposições dialogadas, mesas-redondas, fóruns e plenárias, debates temáticos, oficinas, leitura comentada, produção de textos, dramatizações, portfólios, entre outras (SIQUEIRA-BATISTA; SIQUEIRA-BATISTA, 2009). A esse propósito, pondera-se que nenhum recurso, isoladamente e per se, pode garantir o desenvolvimento da gama de habilidades pretendidas na formação de profissionais da saúde (SIMON et al., 2014). Logo, o mais relevante não é a estratégia metodológica, mas a postura de quem aprende e de quem educa.

Um ponto importante, ainda, a ser considerado é que aquilo que tem se convencionado definir como metodologias ativas de ensino-aprendizagem não pode ser tomado como um conjunto homogêneo, seja no que diz respeito aos pressupostos teóricos ou aos metodológicos (PAIVA et al., 2016). Contudo, um aspecto comum às diferentes estratégias pedagógicas, no âmbito das metodologias ativas, é o fato de que elas apresentam ao estudante desafios que mobilizam seu potencial intelectual (BERBEL, 1998) e sua atitude curiosa e comprometida na relação com o mundo e com os outros. Na educação crítica, a inserção na realidade não intenciona apenas desvelá-la, mas, sim, produzir e recriar conhecimento de forma permanente (FREIRE, 2011). 
Nesse sentido, entre os aspectos positivos da adoção de metodologias ativas de ensinoaprendizagem têm sido indicados a construção da autonomia do estudante, sua qualificação para o trabalho em equipe, a articulação teoria-prática e o desenvolvimento de visão crítica da realidade (PAIVA et al., 2016). No entanto, também têm sido relatadas dificuldades para a utilização dessas metodologias, como engessamento curricular e resistências dos docentes (MESQUITA; MENESES; RAMOS, 2016), além de insegurança dos estudantes (MARIN et al., 2010).

Diante do exposto, reforça-se a pertinência de que sejam socializadas e problematizadas experiências no âmbito dessa temática, como a que se apresenta na próxima seção.

\section{A experiência pedagógica com metodologias ativas de ensino-aprendizagem na saúde}

A experiência que é objeto de reflexão nessa seção foi desenvolvida no primeiro semestre letivo de 2017, em um Programa de Pós-Graduação interdisciplinar em Ciências da Saúde, com cursos de mestrado e doutorado, de uma Universidade do estado de Santa Catarina. Uma das duas linhas de pesquisa do Programa é, precisamente, Formação e Trabalho em Saúde, cuja descrição indica que se dedica a desenvolver pesquisas interdisciplinares acerca dos processos de formação e de trabalho em saúde, estudando questões epistemológicas e fomentando a produção de tecnologias e inovações para a atenção à saúde. No âmbito dessa linha de pesquisa, está a disciplina Formação e Ensino em Saúde, que propõe abordar, conforme é declarado em sua ementa, a historicidade e a formação em saúde, as relações entre currículo, processos de formação e de ensino em saúde, o papel da Universidade na construção do conhecimento e de tecnologias em saúde, o ser e o fazer na docência, e as estratégias de ensinoaprendizagem. Acrescenta-se que o objetivo da disciplina, no escopo do Programa de PósGraduação, é o de refletir sobre os processos de ensino na formação em saúde no contexto da educação superior.

Nessa disciplina, conduzida por professoras com formação profissional na área da saúde e formação para a docência, foram debatidas metodologias ativas de ensino-aprendizagem e aplicadas diferentes estratégias pedagógicas coerentes com essa perspectiva. Com vistas a promover a aproximação dos pós-graduandos com a realidade do ensino superior na área, a disciplina fomentou a elaboração e a aplicação de um plano de aula em um componente curricular de algum curso de graduação da área da saúde, tendo como desafio a utilização de estratégias ativas de ensino-aprendizagem. A esse propósito, um dos objetivos específicos declarados no plano de ensino dessa disciplina era o de planejar e implementar atividades de ensino, utilizando estratégias ativas.

Barbarói, Santa Cruz do Sul, n. 56, p.<104-126>,jan./jun. 2020 
Nesse contexto, diversas experiências foram realizadas pelos pós-graduandos. Este texto se desenvolve centrado na reflexão sobre a prática a partir de uma dessas experiências, desenvolvida junto ao curso de graduação em Psicologia da mesma Universidade. Inicialmente, buscou-se uma disciplina no curso que possibilitasse uma inserção interdisciplinar, visto que as formações de origem das pós-graduandas correspondem à Psicologia e à Enfermagem. Essa questão foi determinante para a escolha da disciplina Psicologia e Saúde Coletiva, ministrada no $8^{\circ}$ período, envolvendo 16 estudantes matriculados, dos quais 10 compareceram na data de realização da prática de ensino realizada.

Foi disponibilizado o período de quatro horas-aula para as pós-graduandas desenvolverem a prática de ensino proposta, que esteve centrada no tema intitulado Núcleo de Apoio à Saúde da Família (NASF): trabalho multiprofissional, interdisciplinar e a inserção do psicólogo.

Ao entrar em contato com os estudantes, no curso de Psicologia, buscou-se sensibilizálos sobre o objetivo e a importância do trabalho na saúde, em específico no NASF, e do trabalho multidisciplinar e interdisciplinar. Os objetivos declarados no plano de aula elaborado eram: a) geral: contextualizar conceitos relacionados ao NASF, ao trabalho multiprofissional e interdisciplinar e à inserção do psicólogo nesse cenário; b) específicos: reconhecer os marcos históricos relacionados à construção e aos objetivos do NASF; compreender a inserção e a atuação do psicólogo no NASF; refletir sobre o trabalho multiprofissional e interdisciplinar em saúde; despertar para as possibilidades e os desafios da inserção do psicólogo na saúde pública. Como estratégias pedagógicas para atingir os objetivos da aula, foram utilizados recursos pautados nas metodologias ativas de ensino-aprendizagem, que promovem maior envolvimento dos estudantes com as atividades propostas e os assuntos abordados (MITRE et al., 2008). Nessa perspectiva, conforme Cotta, Mendonça e Costa (2011), são favorecidos o vínculo e o relacionamento interpessoal entre docente e estudantes.

O ambiente físico da sala de aula foi organizado antes da chegada dos estudantes: mesas e cadeiras foram dispostas em grupos, reunindo entre três e quatro estudantes, sendo que a configuração desses grupos se deu por livre escolha. Observou-se que a composição dos grupos se constituiu por afinidade, proximidade e amizade já estabelecidas entre colegas de turma. Esse é um aspecto que, no trabalho em grupo, pode facilitar o diálogo, pois os participantes já conhecem os papeis exercidos por cada um. Entretanto, pondera-se que provocar a reunião de estudantes de forma aleatória pode contribuir para que eles aprendam a romper barreiras de comunicação, contribuindo para o desenvolvimento de competências ligadas ao saber conviver, 
uma vez que, no mundo do trabalho, provavelmente não terão a liberdade de escolher a equipe com que irão atuar.

Ao iniciar a prática de ensino, as pós-graduandas, assumindo a condição de docentes naquela oportunidade, se apresentaram e esclareceram o grupo quanto ao plano de aula e a proposta para aquele momento de ensino-aprendizagem. Conforme os estudantes se apresentavam, lhes foi solicitado que expusessem brevemente suas expectativas para a aula, entre as quais foram indicadas as seguintes: ter uma aula produtiva; aprofundar conhecimentos; aprender; vivenciar; ampliar o olhar. Foi importante conhecer essas expectativas iniciais dos estudantes na medida em que elas contribuiriam para o processo de avaliação, ao final da prática de ensino realizada.

No planejamento dessa aula, foram incluídas estratégias pedagógicas ativas tempestade de ideias (brainstorming), mapa conceitual, café mundial (world coffee), painel para instigar e possibilitar a participação e a interação entre as pós-graduandas e os estudantes.

A fim de conhecer qual era a compreensão e o conhecimento prévio dos estudantes sobre o tema a ser discutido naquela aula, foi realizada, inicialmente, a estratégia Tempestade de Ideias, fundamentada nas orientações de Anastasiou e Alves (2006). A tempestade de ideias se refere à análise do tema proposto com base na prática social já vivenciada e, portanto, utilizando o conhecimento prévio construído, procurando lançar sobre esse tema o maior número possível de ideias, em um período limitado de tempo, antes de submetê-lo às regras do pensamento lógico (COUTINHO; BOTTENTUITT, 2007).

Além dessa estratégia mobilizar e despertar rapidamente nos estudantes uma vinculação ao tema em estudo (ANASTASIOU; ALVES, 2006), ela contribui para que o educador conforme aponta Freire (2011) - considere o saber dos educandos, problematizando, inclusive, as razões de ser de cada conhecimento. Partir do concreto para mediar a construção de um conhecimento específico é uma estratégia eficaz de envolver ativamente o estudante com o tema proposto. Ainda de acordo com Freire (2011), a ideia, nesse caso, não é a de ficar limitado ao que o estudante já conhece, mas sim partir desse ponto para construir um novo conhecimento que, pautado na reflexão crítica, possa ser transformador da realidade.

Na prática de ensino desenvolvida, a Tempestade de Ideias foi norteada a partir da questão $O$ que eu entendo sobre o NASF?, sendo solicitado aos estudantes que expressassem, em tarjetas de papel colorido previamente distribuídas, o que lhes emergia à mente sobre o tema, não necessitando de subsídios teóricos e profundas reflexões. A cada dois minutos, realizou-se um rodízio das tarjetas, de forma que cada um pudesse contribuir na escrita dos 
demais. Após três rodadas, cada estudante explanou oralmente o que continha sua tarjeta, o que possibilitou a averiguação de inquietações, confusões e o conhecimento sobre o assunto NASF.

Durante a socialização, percebeu-se que os estudantes tinham noções sobre o assunto, porém não havia um conceito alinhado e pautado na Portaria MS n ${ }^{\circ} 154 / 2008^{2}$ (BRASIL, 2008). Alguns referiram como papel do NASF o trabalho de reconhecimento do território, outros entendiam que o NASF só atendia ao público de baixa renda, outros ainda o confundiam com o atendimento do Centro de Atenção Psicossocial (CAPS) ou o das unidades de atendimento como psicoterapia individual e domiciliar.

A partir dessa atividade, percebeu-se a necessidade de utilizar a aula expositiva dialogada para subsidiar teoricamente os conceitos discutidos naquele momento, frente à identificação de algumas interpretações equivocadas e confusas sobre o trabalho no NASF, suas relações com a Estratégia Saúde da Família (ESF), trabalho multiprofissional e interdisciplinar. Ao final dessa etapa, as tarjetas produzidas foram coladas no canto da lousa pelos estudantes para que, posteriormente, fossem retomadas para relacionar essa produção com a próxima atividade, com a intencionalidade de provocar os estudantes à reflexão crítica coletiva sobre o processo de construção de saberes que estavam vivenciando (BARBOSA; MOURA, 2013).

Compreende-se que não seria possível - ou, mesmo, adequado - continuar a discussão sem promover um resgate histórico que permitisse contextualizar o surgimento do NASF no âmbito da saúde pública e a inserção do psicólogo nesse contexto. Ou seja, após a Tempestade de Ideias, era fundamental, conforme recomendam Coutinho e Bottentuitt (2007), submeter o tema abordado às regras do pensamento lógico.

Carabetta Júnior (2013) converge com essa ideia ao afirmar que não é possível compreender um conceito ou objeto de forma isolada. Para o autor, a organização de elementos e suas interações formam uma rede de significados que possibilita a construção de conhecimentos científicos. Nessa perspectiva, para dar sequência às atividades da prática de ensino relatada, foi escolhida a estratégia do Mapa Conceitual.

O Mapa Conceitual é considerado uma estratégia pedagógica que oportuniza que os estudantes integrem e relacionem informações, atribuindo sentido ao tema em estudo. Nesse processo, destaca-se o importante papel da linguagem como elemento facilitador da aprendizagem, na medida em que possibilita “determinar e refletir sobre as operações mentais

\footnotetext{
${ }^{2}$ A experiência relatada nesse manuscrito foi realizada anteriormente à Portaria $\mathrm{n}^{\circ}$ 2.436, de 2017. Por isso, utilizou-se no texto a Portaria MS no 154/2008 e a sigla Núcleo de Apoio à Saúde da Família (NASF), a qual foi alterada para Núcleo Ampliado de Saúde da Família a partir de 2017, com a revisão da Política Nacional de Atenção Básica (PNAB).
}

Barbarói, Santa Cruz do Sul, n. 56, p.<104-126>,jan./jun. 2020 
em níveis mais elevados e abstratos; assimilar por meio da definição do conceito e de seu contexto e facilitar a comunicação cognitiva interpessoal, enquanto permite a uniformidade cultural de conteúdos conceituais" (CARABETTA JÚNIOR, 2013, p. 443).

Para a atividade de construção do Mapa Conceitual, os estudantes foram divididos em três grupos, os quais receberam materiais que representavam distintos marcos históricos da trajetória da saúde no Brasil: os movimentos sociais das décadas de 1970 e 1980, a $8^{\text {a }}$ Conferência Nacional de Saúde, a Constituição Federal - precisamente o artigo 196, que dispõe sobre os direitos relacionados à saúde -, a consolidação do SUS, Leis $n^{\circ} 8.080$ e $n^{\circ} 8.142^{3}$, o Programa Saúde da Família (PSF), a Estratégia Saúde da Família (ESF) e o Núcleo de Apoio à Saúde da Família (NASF), que tem por objetivo ampliar a abrangência e o escopo das ações da atenção básica $(\mathrm{AB})$, bem como sua resolubilidade, apoiando a inserção da Estratégia de Saúde da Família na rede de serviços e o processo de territorialização e regionalização a partir da $\mathrm{AB}$, por meio de atuação e ações intersetoriais e interdisciplinares em promoção da saúde, prevenção de agravos e reabilitação voltada aos indivíduos e coletividades, buscando a resolutividade dos problemas de determinado contexto (BRASIL, 2010).

Cada grupo de estudantes explorou o marco histórico a ele atribuído e, após, o explanou para a turma, em uma exposição dialogada. Utilizando-se da criatividade, os estudantes construíram o Mapa Conceitual em um painel de papel pardo posicionado no centro da lousa, colando termos, desenhando e articulando suas informações com o conhecimento trazido por outros colegas.

Quanto à apresentação gráfica dos Mapas Conceituais, Amoretti (2001, p. 50) explica que se dá na aproximação de conhecimentos a partir de uma hierarquização, construída pelo próprio estudante:

[...] os mapas conceituais demonstraram ser uma ferramenta adequada porque possibilitam ao aluno (e ao professor também) desenvolver um processo cognitivo de aprendizagem em que ele próprio orienta a aquisição de novas informações porque elas estarão diretamente relacionadas com a estrutura de conhecimento prévio.

Assim, mesmo fornecendo alguns materiais para a leitura no momento da aula, assumiuse a ideia de que os estudantes já haviam discutido esses processos em outros momentos, expectativa que foi correspondida ao longo da atividade. O Mapa Conceitual construído em sala seguiu a descrição acima e foi elaborado pelos grupos de estudantes, de forma participativa e colaborativa, promovendo - como afirma Berbel (2011) - um clima agradável, propício ao fortalecimento de um sentido de pertencimento, responsabilização e comprometimento.

\footnotetext{
${ }^{3}$ BRASIL (1990b). 
A discussão desenvolvida contou com a contribuição dos estudantes e das pósgraduandas, na condição de mediadoras do trabalho. A partir dos relatos, percebeu-se que os objetivos pretendidos com a aplicação dessa estratégia - reconhecer os marcos históricos relacionados à construção e aos objetivos do NASF; compreender a inserção e a atuação do psicólogo no NASF - foram atingidos. Foi possível proporcionar um espaço de reflexão aos estudantes, de forma que pudessem reconhecer os marcos históricos do SUS (tais como as Leis $\mathrm{n}^{\circ} 8.080$ e $\mathrm{n}^{\circ}$ 8.142), as estratégias e políticas do Ministério da Saúde (PSF, ESF), bem como o trabalho desenvolvido no atendimento da demanda encaminhada pelas Unidades de Saúde e ESF para o atendimento compartilhado no NASF, por meio da equipe multiprofissional e interdisciplinar.

Ao ser concluída essa atividade, buscou-se relacionar as discussões acerca das ações e atribuições do NASF e do psicólogo nesse cenário à atuação multidisciplinar e interdisciplinar. Para desvelar esses conceitos, foi utilizada a estratégia do World Coffee, adaptando-a à realidade da turma e ao tempo disponível. Essa estratégia busca "despertar a criatividade dos participantes, resultando em um processo estruturado e criativo de geração de ideias com base na colaboração entre os indivíduos" (TEZA et al., 2013, p. 6).

Na realização do World Coffee, foram adotados os passos descritos por Brown e Isaacs (2007): a) contextualizar a atividade e os objetivos a serem conquistados; b) tornar o ambiente confortável, oferecendo folhas flip chart e materiais que possam dar suporte à criatividade dos estudantes, ao responderem aos problemas propostos em cada grupo; c) direcionar a resposta de problemas relacionados à temática por meio de perguntas relevantes (Como você - futuro psicólogo - se imagina trabalhando na saúde pública?, Qual o desafio do trabalho multi e interdisciplinar do psicólogo do NASF? e Qual a potencialidade de ter um psicólogo na equipe do NASF?); d) estimular a participação de todos os envolvidos; e) promover a contribuição e a construção conjunta de respostas; f) possibilitar a escuta de diferentes percepções e o aprofundamento do estudo; g) discutir novas ideias e compartilhar descobertas coletivas.

Nessa atividade, os estudantes foram divididos em três grupos, cada um dos quais elegeu um anfitrião, que deveria permanecer na mesa, enquanto os demais realizassem o rodízio. Isso possibilitou a contribuição de todos os estudantes nas três mesas de discussão e, consequentemente, no debate das três perguntas apresentadas. Ao final da atividade, cada anfitrião apresentou a síntese do que o grupo havia construído. As colocações dos estudantes no debate sobre as expectativas de trabalhar na área da saúde pública evidenciaram uma concepção integral de sujeito e, ainda, apontaram para o reconhecimento da importância de compreender o território, a comunidade e de realizar um trabalho em rede de forma intersetorial, Barbarói, Santa Cruz do Sul, n. 56, p.<104-126>,jan./jun. 2020 
considerando o sujeito na sua singularidade. Mais do que a tomada de consciência, o processo de conscientização promove a inserção crítica do sujeito em uma realidade desmistificada (FREIRE, 2011).

Referente ao desafio do trabalho multi e interdisciplinar do psicólogo, os estudantes expuseram a necessidade de maior interação e vivência em cenários de prática - durante o processo de formação na graduação - com outros cursos da área da saúde. Os estudantes revelaram, ainda, que acreditam haver espaço para ser trabalhada essa troca de saberes para que, enquanto profissionais, consigam reconhecer e levar em consideração o sofrimento do indivíduo e não apenas a patologia. Expuseram também que a potencialidade da atuação do psicólogo no NASF é olhar para a saúde mental, para os direitos humanos, para a subjetividade e a singularidade do sujeito. Para eles, esse profissional tem a capacidade e a habilidade de problematizar, a partir de visão ético-crítica das práticas de cuidado com o usuário, compreendendo que a própria política do SUS tem, muitas vezes, gerado uma generalização dos modos de cuidar, não considerando a singularidade de cada sujeito. Freire (2011) destaca a importância de os homens reconhecerem a realidade não como algo imutável, mas como algo que os desafia. O verdadeiro diálogo entre sujeitos orienta-se para o mundo que é preciso humanizar e implica um compromisso com o pensamento crítico, que percebe a realidade como processo dinâmico de evolução, de transformação.

As falas dos estudantes vêm ao encontro de um dos desafios na formação do profissional, o qual reside na necessidade de formar sujeitos comprometidos com o SUS, com seu fortalecimento e, consequentemente, com a melhoria da vida e da saúde de todos os indivíduos. Na direção de ampliar e diversificar os cenários de prática e aprendizagem, há que se promover a interação entre ensino e serviço. Promover mudanças no processo de formação pressupõe diversificar os cenários de prática, adotar metodologias mais ativas e participativas no processo de ensino e aprendizagem, planejar práticas pedagógicas e intervenções mais adequadas às necessidades do SUS e de seus usuários (BATISTA et al., 2015).

$\mathrm{Na}$ sequência, os estudantes ainda contribuíram com a discussão, gerando um rico debate sobre os temas abordados em sala. Como forma de sintetizar os conteúdos tratados pelos estudantes, foi primordial o aspecto levantado de ter mais disciplinas de saúde pública na matriz curricular e como o trabalho interdisciplinar tem um caminho desafiador a percorrer para se aproximar daquilo que se espera nos serviços do SUS.

Reforçando a percepção dos estudantes, pesquisas recentes têm destacado um ponto em comum: o descompasso da formação profissional com a posterior atuação do psicólogo brasileiro na área da saúde pública (SOUTO; BATISTA; BATISTA, 2014; AMENDOLA, Barbarói, Santa Cruz do Sul, n. 56, p.<104-126>,jan./jun. 2020 
2014). Poppe e Batista (2012) complementam que, para qualificar a formação profissional, é fundamental que as práticas sejam vivenciadas de forma interdisciplinar nesse processo, atendendo às novas demandas do SUS.

Nessa perspectiva, o processo de formação precisa favorecer a aproximação entre o estudante (futuro profissional) e o serviço, incentivando o diálogo constante entre a universidade e a rede de saúde, diversificando os cenários de prática (BATISTA; CARMONA; FONSECA, 2014). Assim, é importante que a formação crie e promova "[...] espaços de rupturas na lógica de busca de uma cientificidade traduzida em instrumentos e técnicas que deem respaldo a esse novo lugar de saber" (REIS; GUARESCHI, 2010, p. 865) e que promovam autonomia e criticidade do estudante.

O desafio maior da educação atual tem sido, exatamente, favorecer a coalização com o coletivo, com clara inter-relação no desenvolvimento da autonomia individual, ou seja: "O ensinar exige respeito à autonomia e à dignidade de cada sujeito, especialmente no âmago de uma abordagem progressiva" (MITRE et al., 2008, p. 2135), o que é um imperativo ético e não apenas um favor que podemos escolher se iremos conceder ou não ao outro (FREIRE, 2011).

A partir dessas estratégias pedagógicas, as pós-graduandas buscaram exercer, como docentes, o papel de mediadoras do processo, condição em que se deve desenvolver flexibilidade e intuição para lidar com a incerteza, a provisoriedade e o volume crescente de informações na sua área de atuação, além de proporcionar um espaço de reflexão crítica para que os estudantes assumam o protagonismo no seu processo de aprendizagem (ANASTASIOU; ALVES, 2006).

Em paralelo, os estudantes puderam realizar a avaliação da prática de ensino desenvolvida (avaliação da aula), utilizando-se de um Painel Avaliativo que possuía espaços para a colagem de imagens com símbolos de curtir e não curtir, termos utilizados na linguagem da internet e que indicam aprovação ou não de algo, ao lado dos tópicos propostos, como gestão do tempo e metodologia de ensino, entre outros.

Ao final, foram retomadas as expectativas indicadas pelos estudantes no início da aula, cotejando-as com o Painel Avaliativo para realizar um processo de avaliação dialogada que possibilitasse a expressão, autoavaliação e feedback dos estudantes. Conforme enfatizam Mitre et al. (2008), os apontamentos e o diálogo têm sido utilizados como estratégias em que docentes e estudantes podem registrar o desenvolvimento da avaliação no processo, em uma perspectiva formativa. Há que se atentar para a avaliação, no sentido de atribuir-lhe efetivamente um papel pedagógico, como recurso metodológico que permita a reorientação do processo de ensinoaprendizagem em ato (VASCONCELLOS, 2006). Caso contrário, desperdiça-se a Barbarói, Santa Cruz do Sul, n. 56, p.<104-126>,jan./jun. 2020 
oportunidade de qualificar os processos de ensino-aprendizagem a partir da avaliação, a qual fica relegada a uma função burocrática.

Os estudantes não só avaliaram a prática de ensino desenvolvida como um todo, mas também discutiram a aplicação de estratégias ativas de ensino-aprendizagem. Para eles, as atividades realizadas foram atrativas, suas expectativas iniciais foram atendidas e a didática utilizada na aula foi interessante, fazendo com que se envolvessem e participassem, expressando suas opiniões sem receio. Além disso, apontaram que o tempo passou sem que percebessem, o que parece revelar que aquele foi um tempo agradável de aprendizagem.

Contudo, deve ser registrado que um dos estudantes expressou a ideia de que a natureza dos conteúdos da Psicologia demanda metodologias tradicionais de ensino. Ao mesmo tempo, o professor responsável pelo componente curricular afirmou que, devido à carga horária, a aula expositiva acaba sendo mais utilizada, pois as metodologias ativas exigem mais tempo para planejamento, organização e desenvolvimento das aulas. Essas afirmações podem explicar as resistências e dificuldades relativas à adoção de metodologias ativas de ensino-aprendizagem, anteriormente referidas por Mesquita, Meneses e Ramos (2016) e por Marin et al. (2010).

Salienta-se, no entanto, que os estudantes, no processo de autoavaliação, quanto ao quesito participação e apropriação do conteúdo trabalhado, afirmaram ter se esforçado e envolvido com a atividade, o que proporcionou que conseguissem fazer conexão com a prática de estágio e a realidade do profissional. Cabe ressaltar que, na avaliação das pós-graduandas, os estudantes apresentaram "[...] iniciativa criadora, curiosidade científica, espírito críticoreflexivo, capacidade para autoavaliação, cooperação para o trabalho em equipe, senso de responsabilidade, ética, que são características fundamentais a serem desenvolvidas em seu perfil” (MITRE et al., 2008, p. 2137).

Logo, pondera-se que a prática de ensino realizada foi exitosa quanto aos objetivos da disciplina Formação e Ensino em Saúde, na medida em que proporcionou às pós-graduandas a reflexão sobre os processos de ensino na formação em saúde no contexto da educação superior ao mobilizá-las ao planejamento e à implementação de atividades de ensino, utilizando estratégias ativas.

Da mesma forma, considera-se que a experiência foi bem-sucedida e produtiva em termos do processo de ensino-aprendizagem na disciplina Psicologia e Saúde Coletiva, conforme a avaliação das pós-graduandas e dos estudantes. Porém, evidentemente, restam desafios a serem trabalhados nesse contexto, alguns dos quais apontados pelo mesmo processo de avaliação, como os empecilhos de ordem curricular (relativos à carga horária da disciplina) e a percepção discente de que os conteúdos da Psicologia são densos e por isso não seriam Barbarói, Santa Cruz do Sul, n. 56, p.<104-126>,jan./jun. 2020 
apropriados às metodologias ativas. Tais aspectos apontam para a necessidade de sensibilização de três atores quanto à implementação de metodologias ativas: instituição, educador e educando.

Pondera-se que essa experiência vivenciada por estudantes da graduação e da pósgraduação assumiu um caráter inovador, pois possibilitou a ampliação de conhecimentos quanto às estratégias ativas e a sua aplicabilidade, o que tornou o processo de ensino mais produtivo. O conjunto de técnicas e estratégias utilizadas assumiu uma perspectiva transformadora, pelas interações estabelecidas no planejar, conduzir, experienciar e avaliar o processo realizado. Ainda, essa estratégia se configurou como um espaço para o debate e a problematização da formação docente na pós-graduação stricto sensu por meio da disciplina Formação e Ensino em Saúde.

Sobre os desafios apontados, algumas considerações podem ser tecidas. No que diz respeito à alegação de que metodologias ativas requerem maior tempo de planejamento, organização e implementação das atividades de ensino-aprendizagem, pode-se supor que isso se deva mais à pouca familiaridade com as metodologias. Ou seja, à medida que metodologias ativas de ensino-aprendizagem forem incorporadas à prática docente, a demanda de tempo (e sua relação com a carga horária das disciplinas) tornar-se-á um empecilho de menor monta no processo. Cabe destacar, ainda, que a prática de ensino relatada apresentou limitações quanto ao aspecto do tempo, visto que foram aplicadas várias estratégias pedagógicas em um curto período (quatro horas-aula). Logo, em condições rotineiras, seria o caso de se propor uma organização mais condizente com o tempo disponível. Além disso, o tempo não pode ser assumido como um limitante para a adoção de metodologias ativas, se for considerado que mesmo uma aula expositiva (desde que efetivamente) dialogada pode ser tão ativa quanto outras estratégias mais explicitamente reconhecidas como tal, a depender das intencionalidades, atitudes e posturas de professores e estudantes e de como ela será integrada no processo global de formação.

Quanto à ideia de que determinados conteúdos não seriam próprios para serem abordados por meio de metodologias ativas, pondera-se que isso possa, de fato, ocorrer, mas apenas na relação com o tempo disponível. Dito de outra forma, compreende-se que todos os conteúdos podem ser desenvolvidos por meio de metodologias ativas, mas que a organização curricular predominante na educação superior não se apresenta oportuna e favorável para isso.

Assim, uma alternativa viável seria a seleção de tópicos de conteúdo para serem trabalhados por meio de estratégias que demandam mais tempo, enquanto outros poderiam ser abordados por meio de aulas efetivamente dialogadas. Nessa direção, um dos desafios é Barbarói, Santa Cruz do Sul, n. 56, p.<104-126>,jan./jun. 2020 
promover maior comprometimento dos estudantes nos espaços para além da sala de aula, a partir de disparadores que instiguem sua curiosidade e corresponsabilização. Dessa forma, a sala de aula se constituiria em um espaço colaborativo, de síntese e reelaboração de saberes e práticas.

Obviamente, para que metodologias ativas possam ser incorporadas à práxis docente na educação superior na saúde em uma perspectiva crítica, um elemento fundamental a ser considerado é a formação para a docência. Para tanto, reforça-se o papel da pós-graduação stricto sensu, por meio da oferta de disciplinas que visem a essa formação e que, para além do debate teórico sobre o tema ou sobre suas dimensões burocráticas, proporcionem oportunidades para a vivência da docência em cenários reais, em um movimento de ação e reflexão que, de fato, contribua para a indução de mudanças na educação superior em saúde.

\section{Considerações finais}

A partir do desenvolvimento da disciplina Formação e Ensino em Saúde e da prática de ensino realizada, evidenciou-se que a utilização de estratégias de ensino-aprendizagem que incentivam o protagonismo favorecem a construção de conhecimento por meio da apropriação crítica do conteúdo e promovem a reflexão sobre a relação do sujeito com esse conhecimento e sobre sua função enquanto ser social, político e transformador da realidade.

Há, certamente, um longo caminho a ser construído, especialmente quando se considera a formação do profissional da saúde para a docência. No entanto, pondera-se que é necessário mudar a prática se o que se pretende é mudar a realidade. Quando o professor passa a adotar estratégias horizontais e problematizadoras, ele se despe frente aos estudantes e se sujeita a enfrentar desafios que nem sempre estão presentes em uma aula tradicional com atitudes transmissivas, em que ele tem o controle sobre o conteúdo, o tempo, as relações e o processo de comunicação, podendo impor a cultura do silêncio. Quando o docente opta por proporcionar um ambiente de reflexão, ele precisa se preparar para lidar com imprevistos, bem como para garantir que o processo de ensino-aprendizagem seja efetivo quanto ao embasamento teórico que o sustenta e aos objetivos da formação.

Percebe-se, portanto, a relevância da experiência desenvolvida e da disciplina que desafiou os pós-graduandos a realizá-la, ressaltando-se que a formação para o ensino deveria ser inerente a todo e qualquer programa que se destine a preparar profissionais da saúde não só para a pesquisa, mas também para a docência. Apesar de não ter sido possível entrar em contato com outras realidades de ensino na saúde, devido ao tempo e à condição de pós-graduandas em 
processo de formação para a docência, essa experiência proporcionou, certamente, o despertar para novas práticas pedagógicas e para uma nova forma de ser docente.

À guisa de conclusão, retoma-se o objetivo deste texto - problematizar as possibilidades de a pós-graduação stricto sensu assumir um papel protagonista na formação para a docência na área da saúde -, para reafirmar a importância de que outros estudos venham a ser produzidos no âmbito deste tema, de forma que a pós-graduação possa ser fortalecida em sua responsabilidade e em seu potencial de se constituir como lócus de formação de professores para a educação superior.

\title{
THE POST-GRADUATION AS LÓCUS OF TRAINING FOR TEACHING: AN EXPERIENCE WITH TEACHING-LEARNING ACTIVE METHODOLOGIES IN HEALTH AREA
}

\begin{abstract}
The professional profile aimed by the Unified Health System (Sistema Único de Saúde, in Portuguese) requires a training based on problematization and that recognizes the student as responsible for the construction of knowledge, promoting his development beyond the technical-scientific and procedural dimensions. This paper discusses a teaching practice carried out in higher education, from a postgraduate program in the health area, based on active teaching-learning methodologies. The objective of this work was to problematize the possibilities of the postgraduate taking a leading role in training for teaching in the health area. The text presents the assumptions of the active teaching-learning methodologies that underlie the teaching practice and, when reporting the experience of teaching carried out in an undergraduate course, problematizes it. The developed reflection evidences the importance of the post-graduation assuming the privileged locus condition for teacher training.
\end{abstract}

Keywords: Teaching practice; High education; Educational models.

\section{REFERÊNCIAS}

ABRAHÃO, Ana Lúcia; MERHY, Emerson Elias. Formação em saúde e micropolítica: sobre conceitos-ferramentas na prática de ensinar. Interface, Botucatu, v. 18, n. 49, p. 313-324, jun. 2014.

AMENDOLA, Márcia Ferreira. Formação em Psicologia, demandas sociais contemporâneas e ética: uma perspectiva. Psicologia: Ciência e Profissão, Brasília, v. 34, n. 4, p. 971-983, out./dez. 2014.

AMORETTI, Maria Suzana Mark. Protótipos e estereótipos: aprendizagem de conceitos. Mapas conceituais: experiência em Educação a Distância. Informática na Educação: teoria \& prática, Porto Alegre, v. 4, n. 2, p. 49-55, jul./dez. 2001.

ANASTASIOU, Léa das Graças Camargos; ALVES, Leonir Pessate. Estratégias de ensinagem. In: ANASTASIOU, Léa das Graças Camargos; ALVES, Leonir Pessate. (Orgs.). Processos de ensinagem na universidade: pressupostos para as estratégias de trabalho em aula. 6.ed. Joinville: UNIVILLE, 2006. p. 67-100. 
BATISTA, Sylvia Helena Souza da Silva et al. Formação em Saúde: reflexões a partir dos programas Pró-Saúde e PET-Saúde. Interface, Botucatu, v. 19, supl. 1, p. 743-752, dez. 2015.

BATISTA, Cássia Beatriz; CARMONA, Daniela Souza; FONSECA, Sara Lopes. Formação em saúde e os cenários de aprendizagem no curso de Psicologia. Psicologia Argumento, Curitiba, v. 32, n. 78, p. 17-25, jul./set. 2014.

BACKES, Vânia Marli Schubert et al. Expressões do conhecimento didático do conteúdo de um professor experimentado de enfermagem. Texto \& Contexto Enfermagem, Florianópolis, v. 22, n.3, p. 804-810, jul./set. 2013.

BARBOSA, Eduardo Fernandes; MOURA, Dácio Guimarães. Metodologias ativas de aprendizagem na Educação Profissional e Tecnológica. Boletim Técnico do Senac, Rio de Janeiro, v. 39, n. 2, p. 48-67, maio/ago. 2013.

BERBEL, Neusi Aparecida Navas. A problematização e a aprendizagem baseada em problemas: diferentes termos ou diferentes caminhos? Interface, Botucatu, v. 2, n. 2, p. 139154, fev. 1998.

BERBEL, Neusi Aparecida Navas. As metodologias ativas e a promoção da autonomia de estudantes. Semina, Londrina, v. 32, n. 1, p. 25-40, jan./jun. 2011.

BRASIL. Ministério da Saúde. Gabinete do Ministro. Portaria n. 154, de 24 de janeiro de 2008. 2008. Cria os Núcleos de Apoio à Saúde da Família - NASF. Disponível em: http://bvsms.saude.gov.br/bvs/saudelegis/gm/2008/prt0154_24_01_2008.html Acesso em: 21 mar. 2018.

BRASIL. Presidência da República. Casa Civil. Subchefia para Assuntos Jurídicos.

Constituição da República Federativa do Brasil. 1988. Disponível em:

http://www.planalto.gov.br/ccivil_03/constituicao/constituicao.htm Acesso em: 26 mar. 2018.

BRASIL. Presidência da República. Casa Civil. Subchefia para Assuntos Jurídicos. Lei n. 8.080, de 19 de setembro de 1990. 1990a. Dispõe sobre as condições para promoção, proteção e recuperação da saúde, a organização e o funcionamento dos serviços correspondentes e dá outras providências. Disponível em:

http://www.planalto.gov.br/ccivil_03/leis/18080.htm Acesso em: 26 mar. 2018.

BRASIL. Presidência da República. Casa Civil. Subchefia para Assuntos Jurídicos. Lei n. 8.142, de 28 de dezembro de 1990. 1990b. Dispõe sobre a participação da comunidade na gestão do Sistema Único de Saúde (SUS) e sobre as transferências intergovernamentais de recursos financeiros na área da saúde e dá outras providências. Disponível em: http://www.planalto.gov.br/ccivil_03/leis/18142.htm Acesso em: 26 mar. 2018.

BRASIL. Presidência da República. Casa Civil. Subchefia para Assuntos Jurídicos. Lei n. 9.394, de 20 de dezembro de 1996. 1996. Estabelece as Diretrizes e Bases da Educação Nacional. Disponível em: http://www.planalto.gov.br/Ccivil_03/leis/L9394.htm Acesso em: 26 mar. 2018.

BRASIL. Conselho Nacional de Educação. Câmara de Educação Superior. Resolução CNE/CES n. 3, de 07 de novembro de 2001. 2001. Institui Diretrizes Curriculares Nacionais 
do Curso de Graduação em Enfermagem. Disponível em:

http://portal.mec.gov.br/cne/arquivos/pdf/CES03.pdf Acesso em: 26 mar. 2018.

BRASIL. Ministério da Saúde. Secretaria de Atenção à Saúde. Departamento de Atenção Básica. Diretrizes do NASF: Núcleo de Apoio a Saúde da Família. Cadernos de Atenção Básica n. 27. Brasília: Ministério da Saúde, 2010.

BROWN, Juanita; ISAACS, David. O World Café: dando forma ao nosso futuro por meio de conversações significativas e estratégicas. São Paulo: Cultrix, 2007.

CARABETTA JÚNIOR, Valter. A Utilização de Mapas Conceituais como Recurso Didático para a Construção e Inter-Relação de Conceitos. Revista Brasileira de Educação Médica, Brasília, v. 37, n. 3, p. 441-447, jul./set. 2013.

CECCIM, Ricardo Burg; FEUERWERKER, Laura Camargo Macruz. O quadrilátero da formação para a área da saúde: ensino, gestão, atenção e controle social. Physis: Revista de Saúde Coletiva, Rio de Janeiro, v. 14, n. 1, p. 41-65, jan./jun. 2004.

COTTA, Rosangela Minarde Mitre; MENDONÇA, Erica Toledo; COSTA, Glauce Dias. Portfólios reflexivos: construindo competências para o trabalho no Sistema Único de Saúde. Revista Panamericana de Salud Pública, Washington, v. 30, n. 5, p. 415-421, set./out. 2011.

COUTINHO, Clara Pereira; BOTTENTUIT, João Batista. Utilização da técnica do Brainstorming na introdução de um modelo de E/B-Learning numa escola Profissional Portuguesa: a perspectiva de professores e alunos. In: ENCONTRO INTERNACIONAL DISCURSO METODOLOGIA E TECNOLOGIA, 2007, Miranda do Douro, Portugal, 2007. Actas... Miranda do Douro, Portugal: Centro de Estudos António Maria Mourinho, 2007. p. $102-118$.

DIAS, Henrique Sant'Anna; LIMA, Luciana Dias; TEIXEIRA, Marcia. A trajetória da política nacional de reorientação da formação profissional em saúde no SUS. Ciência \& Saúde Coletiva, Rio de Janeiro, v. 18, n. 6, p. 1613-1624. jun. 2013.

FREIRE, P. Pedagogia da Autonomia. 30.ed. São Paulo: Paz e Terra, 2011.

FREIRE, P. Pedagogia do Oprimido. 17.ed. Rio de Janeiro: Paz e Terra, 2005.

FREITAS, Paula Hübner et al. Repercussões do PET-Saúde na formação de estudantes da área da saúde. Escola Anna Nery, Rio de Janeiro, v. 17, n. 3, p. 496-504, ago. 2013.

FURTADO, Maria Edilânia Matos Ferreira; CARVALHO, Liliane Brandão. O psicólogo no NASF: potencialidades e desafios de um profissional de referência. Revista Psicologia e Saúde, Campo Grande, v. 7, n. 1, p. 09-17, jun. 2015.

GENTIL, Danielly Ferri; ABILIO, Elenita Sureke; CORDEIRO, Maria José de Jesus Alves. Limites e desafios curriculares na formação de profissionais para atuar no Sistema Único de Saúde. Revista Interfaces da Educação, Paranaíba, v. 6, n. 17, p. 77-96, maio/ago. 2015. 
GIGANTE, Renata Lúcia; CAMPOS, Gastão Wagner de Sousa. Política de formação e educação permanente em saúde no Brasil: bases legais e referências teóricas. Trabalho, Educação e Saúde, Rio de Janeiro, v. 14, n. 3, p. 747-763, set./dez. 2016.

HORA, Dinair Leal et al. Propostas inovadoras na formação do profissional para o Sistema Único de Saúde. Trabalho, Educação e Saúde, Rio de Janeiro, v. 11, n. 3, p. 471486, set./dez. 2013.

LEAL, Juliana Alves Leite et al. Novos espaços de reorientação para formação em saúde: vivências de estudantes. Interface, Botucatu, n. 19, v. 53, p. 361-371, abr./jun. 2015.

LIMA, Valéria Vernaschi. Espiral construtivista: uma metodologia ativa de ensinoaprendizagem. Interface, Botucatu, v. 21, n. 61, p. 421-434, abr./jun. 2017.

MARIN, Maria José Sanches et al. Aspectos das fortalezas e fragilidades no uso das metodologias ativas de aprendizagem. Revista Brasileira de Educação Médica, Brasília, v. 34, n. 1, p. 13-20, jan./mar. 2010.

MESQUITA, Simone Karine da Costa; MENESES, Rejane Millions Viana; RAMOS, Déborah Karollyne Ribeiro. Metodologias ativas de ensino/aprendizagem: dificuldades de docentes de um curso de enfermagem. Trabalho, Educação e Saúde, Rio de Janeiro, v. 14, n. 2, p. 473-486, mai./ago. 2016.

MITRE, Sandra Minardi et al. Metodologias ativas de ensino-aprendizagem na formação profissional em saúde: debates atuais. Ciência \& Saúde Coletiva, Rio de Janeiro, v. 13, n. 2, p. 2133-2144, dez. 2008.

PAGLIOSA, Fernando Luiz; DA ROS, Marco Aurélio. O relatório Flexner: para o bem e para o mal. Revista Brasileira de Educação Médica, Brasília, v. 32, n. 4, p. 492-499, out./dez. 2008.

PAIVA, Marlla Rúbya Ferreira et al. Metodologias ativas de ensino-aprendizagem: revisão integrativa. SANARE, Sobral, v. 15, n. 2, 145-153, jun./dez. 2016.

PAULINO, Valquíria Coelho Pina et al. Formação e saberes para a docência nos cursos de graduação em enfermagem. Journal Health NPEPS, Tangará da Serra, v. 2, n. 1, p. 272-284, jan./jun. 2017.

POPPE, Andreia Regina Soares; BATISTA, Sylvia Helena Souza da Silva. Formação em Psicologia no contexto das Diretrizes Curriculares Nacionais: uma discussão sobre os cenários de prática em saúde. Psicologia: Ciência e Profissão, Brasília, v. 32, n. 4, p. 986-999, out./dez. 2012.

REIS, Carolina dos; GUARESCHI, Neuza Maria de Fátima. Encontros e desencontros entre Psicologia e Política: formando, deformando e transformando profissionais de saúde.

Psicologia: Ciência e Profissão, Brasília, v. 30, n. 4, p. 854-867, out./dez. 2010.

SIMON, Eduardo et al. Metodologias ativas de ensino-aprendizagem e educação popular: encontros e desencontros no contexto da formação dos profissionais de saúde. Interface, Botucatu, v. 18, supl. 2, p. 1355-1364, dez. 2014. 
SIQUEIRA-BATISTA, Rodrigo; SIQUEIRA-BATISTA, Rômulo. Os anéis da serpente: a aprendizagem baseada em problemas e as sociedades de controle. Ciência \& Saúde Coletiva, Rio de Janeiro, v. 14, n. 4, p. 1183-1192, jul./ago. 2009.

SOUTO, Thamires da Silva; BATISTA, Sylvia Helena; BATISTA, Nildo Alves. A educação interprofissional na formação em Psicologia: olhares de estudantes. Psicologia: Ciência e Profissão, Brasília, v. 34, n. 1, p. 32-45, jan./mar. 2014.

TEZA, Pierry et al. Geração de ideias: aplicação da técnica world café. International Journal of Knowledge Engineering and Management, Florianópolis, v. 3, n. 3, p. 1-14, jul./out. 2013.

TREVISO, Patrícia; COSTA, Bartira Ercília Pinheiro. Percepção de profissionais da área da saúde sobre a formação em sua atividade docente. Texto \& Contexto Enfermagem, Florianópolis, v. 26, n. 1, p. 1-9, abr. 2017.

VASCONCELLOS, Celso dos Santos. Avaliação: concepção dialética-libertadora dos processos de avaliação escolar. 16.ed. São Paulo: Libertad, 2006.

Data de recebimento: $05 / 03 / 2020$

Data de aceite: 01/06/2020

\section{Sobre as autoras:}

Maria Eduarda de Carli Rodrigues é graduada em Enfermagem pela Universidade Estadual do Oeste do Paraná (Unioeste), especialista em Docência na Educação Superior pela Universidade Comunitária da Região de Chapecó (Unochapecó) e em Enfermagem em UTI (Faculdade UNYLEYA). É Mestre pelo Programa de Pós-Graduação em Ciências da Saúde da Unochapecó e Doutoranda do Programa de Pós-Graduação em Enfermagem da Universidade Federal de Santa Catarina (UFSC). Endereço Eletrônico: mariadecarli@unochapeco.edu.br

Raquel Antunes de Mello é Mestre pelo Programa de Pós-Graduação em Ciências da Saúde da Universidade Comunitária da Região de Chapecó (Unochapecó), Especialista em Gestão de Pessoas (2009) pela Fundação Getúlio Vargas (FGV) e em Dinâmica de Grupos (2015) pela Sociedade Brasileira de Dinâmica de Grupo (SBDG). Graduada (2008) em Psicologia (Unochapecó), atualmente é docente do ensino superior em Gestão de Recursos Humanos e Processos Gerenciais e do ensino de pós-graduação lato sensu em Gestão Estratégica de Pessoas do Serviço Nacional de Aprendizagem Comercial (SENAC). Endereço Eletrônico: quelmello@unochapeco.edu.br

Carla Rosane Paz Arruda Teo é docente permanente dos cursos de mestrado e doutorado do Programa de Pós-Graduação em Ciências da Saúde da Universidade Comunitária da Região de Chapecó (Unochapecó). Na graduação, atua nos cursos de Medicina e Nutrição da mesma Universidade. É Doutora (2007) e Mestre (2002) em Ciência de Alimentos pela Universidade Estadual de Londrina (UEL), com pós-doutorado em Nutrição em Saúde Pública (FSPUSP/2013). Nutricionista pela Universidade Federal de Pelotas (UFPel/1988), com Especialização em Educação Básica (1998), Docência na Educação Superior (2009), Produção e Revisão de Textos (2009) e Preceptoria no SUS (IEP-HSL/2017). Compõe o Banco de 
Avaliadores do Sistema Nacional de Avaliação da Educação Superior (BASis) e o Banco Nacional de elaboradores e revisores técnico-pedagógicos de Itens (BNI) do ENADE. Endereço Eletrônico: carlateo@unochapeco.edu.br

Maria Elisabeth Kleba é enfermeira (UFSC, 1981), Doutora em Filosofia pela Universidade de Bremen (Uni-Bremen/Alemanha, 2000), membro do Grupo Interinstitucional Sementes para a Pesquisa Colaborativa Baseada na Comunidade (CBPR), da Rede de Pesquisa-Ação Participativa do Brasil (Rede PAP Brasil) e da International Collaboration on Participatory Health Research (ICPHR). Atua como consultora e educadora autônoma nas áreas de gestão de políticas públicas e participação social, e de educação permanente em saúde. Endereço Eletrônico: lkleba@unochapeco.edu.br

Fátima Ferretti é docente permanente dos cursos de mestrado e doutorado do Programa de PósGraduação em Ciências da Saúde da Universidade Comunitária da Região de Chapecó (Unochapecó). É Doutora (2011) em Saúde Coletiva pela Universidade Federal de São Paulo (UNIFESP) e fisioterapeuta (1995) pela Universidade de Cruz Alta (UNICRUZ). Atualmente, compõe o Banco Nacional de Avaliadores Institucionais e de Curso (MEC), é membro da International Collaboration for Participatory Health Research (ICPHR) e Editora Chefe da Revista FisiSenectus. Endereço Eletrônico: ferrettifisio@yahoo.com.br 